\title{
Injury to the posterior cruciate ligament: biomechanics, diagnosis, treatment and prevention of secondary osteoarthritis
}

\author{
A.V. Korolev ${ }^{1,2}$, A.P. Afanasyev ${ }^{1}$, D.O. Il'in $^{1}$, D.O. Gerasimov ${ }^{1}$, M.S. Ryazantsev ${ }^{1}$, P.M. Kadantsev ${ }^{1,2}$ \\ ${ }^{1}$ European Clinic of Sports Traumatology and Orthopaedics (ECSTO), Moscow, Russian Federation, \\ ${ }^{2}$ Peoples Friendship University of Russia, Moscow, Russian Federation
}

\begin{abstract}
The literature was reviewed for reports on the pathogenesis, diagnosis and treatment of injuries to the posterior cruciate ligament (PCL). PCL is the largest intra-articular ligament in the knee joint and has good tensile mechanical properties. Optimal diagnosis and appropriate treatment strategies for PCL injury are discussed. Nonoperative treatment of isolated PCL injuries is associated with a significant risk of degeneration of the knee structures and impaired function. A comprehensive line of PCL reconstruction options are offered for the surgical approach to PCL reconstruction to restore functional joint stability in the knee. Literature data on protective effect of glucosamine, chondroitin sulfate in the prevention of secondary knee osteoarthritis caused by PCL ruptures were reviewed.

Keywords: knee joint, ligament injury, posterior cruciate ligament, posterior cruciate ligament rupture, nonoperative treatment, surgical treatment, chondroprotection, secondary osteoarthritis, bracing
\end{abstract}

\section{INTRODUCTION}

Knee injury is a common concern for which $13 \%$ of individuals would seek medical assistance [1-3]. About $60 \%$ of population present with knee pain and disturbed knee function throughout the lifetime [2-4]. Traumatic ligament injuries are a common cause of morbidity in professional athletes $[2,5,6]$. The most common types of sports sprains happen in the ankle or in the knee. Although ankle sprains are by far more common than knee sprains, many knee injuries can be successfully repaired with surgical approaches that frequently cause unsatisfactory results $[5,6]$. Knee injury is more common among working-age males and usually results from traumatic injury and degenerative joint changes [7-9]. Road traffic accident accounts for majority of the cases of knee injuries that are equally common in drivers, car occupants and pedestrians

The most common pattern of injury is reported to be dashboard injuries in motor vehicle accidents, contact sports like soccer [4]. Excessive weight, specific occupational habits, previous history of knee injury also increase the likelihood of development of gonarthrosis $[9,10]$. The factors that play a role in the development of degenerative changes in the knee are ligament deficiency, posttraumatic joint laxity with a resultant varus alignment. Signs of pathological changes in the articular cartilage and the bone are seen in more than $50 \%$ of patients with a disturbed knee function [11].

Posterior cruciate ligament (PCL) tears comprise $3 \%$ of knee injuries and $38 \%$ of acute traumatic knee hemarthroses $[4,5]$. These injuries rarely occur in isolation, and up to $95 \%$ of PCL tears occur in combination with other ligament ruptures. PCL tears are increasingly being recognized as source of morbidity and reduced function because of persistent instability, pain and development of degenerative joint disease [12].

The objective of the article was to review literature for reports on the pathogenesis, diagnosis and treatment of injuries to the PCL.

PCL is the largest intra-articular ligament in the knee joint and has good tensile mechanical properties. The PCL is comprised of two bundles: the larger anterolateral bundle (ALB) and smaller posteromedial bundle (PMB). The size of the femoral attachment of the ALB is nearly twice the size of its tibial attachment and has been reported to range from 112 to $118 \mathrm{~mm}^{2}[13,14]$. The center of the femoral ALB footprint is located $7.4 \mathrm{~mm}$ from the trochlear point, $11.0 \mathrm{~mm}$ from the medial arch point, and $7.9 \mathrm{~mm}$ from the distal articular cartilage. ALB tibial

Korolev A.V., Afanasyev A.P., Il'in D.O., Gerasimov D.O., Ryazantsev M.S., Kadantsev P.M. Injury to the posterior cruciate ligament: biomechanics, diagnosis, treatment and prevention of secondary osteoarthritis. Genij Ortopedii, 2020, vol. 26, no 3, pp. 413-419. DOI 10.18019/1028-4427-2020-26-3-413-419 
attachment center is located $6.1 \mathrm{~mm}$ posterior to the shiny white fibers of the posterior medial meniscus root, $4.9 \mathrm{~mm}$ from the bundle ridge which separates both bundles [14].

The area of the PMB femoral attachment is between $60 \mathrm{~mm}^{2}$ and $90 \mathrm{~mm}^{2}$ in size and is located between the anterior and posterior meniscofemoral ligaments. The femoral PMB center is located $11.1 \mathrm{~mm}$ from the medial arch point and $10.8 \mathrm{~mm}$ from the posterior point of the articular cartilage margin. The PMB tibial attachment center is located $4.4 \mathrm{~mm}$ of the posterior tibia and $3.1 \mathrm{~mm}$ lateral from the medial groove of the medial tibial plateau articular surface [14]. These measures have biomechanical and surgical implications, because an anatomic reconstruction of the ALB and PMB better restores native knee kinematics and has been reported to improve clinical outcomes.

Functionally, the PCL is a primary restraint to posterior tibial translation at all flexion angles. It also has a role in primary restraint for internal rotation beyond $90^{\circ}$ and a supplemental restraint to external tibial rotation beyond $90^{\circ}$ of flexion [13]. Both bundles have a synergistic behavior during knee range of motion [14-16]. The strength of PCL is added by frequently identified 1 or 2 meniscofemoral ligaments known as ligaments of Humphry and Wrisberg. The ligaments are found to be present in $70-80 \%$ of the knee joints.

Historically, the ALB and PMB were believed to function independently in a reciprocal nature, with the ALB primarily functioning in deep flexion and the PMB in extension [15]. However, recent biomechanical studies have demonstrated that both the ALB and PMB assume a significant role in resisting posterior tibial translation at all flexion angles. This suggests a codominant relationship between both bundles and, therefore, both assume a significant role in knee stability [17].

The ALB is the main resistant to posterior tibial translation between $70^{\circ}$ and $105^{\circ}$, while the PMB is the main resistant between $0^{\circ}$ and $15^{\circ}$. This distribution of forces between the two bundles has surgical implications at the time of graft fixation during anatomic double-bundle PCL reconstructions. Kennedy et al. (2013) reported in a biomechanical study that when both bundles were sectioned, $11.7 \mathrm{~mm}$ of posterior tibial translation at $90^{\circ}$ was observed. This suggests that to have a grade III PCL injury, both bundles need to be torn.

The PCL has recently been reported to have a more important role for rotational stability than previously thought. It restricts internal rotation at all flexion angles, and the PMB was reported to be the most important bundle for controlling rotation beyond $90^{\circ}$ of flexion [18]. The combination of symptoms, history with the focus on mechanism of injury and clinical examination tests, with the addition of noninvasive imaging, invasive procedures including intraoperative repair is vital to make an accurate diagnosis of PCL deficiency. However, the diagnosis can be difficult due to a late presentation of athletic injury.

Knee extension deficit is indicative of a knee injury, ligament or meniscus tear as well as combined injuries to the articular structures [18]. Joint instability is another substantial sign of impaired ligamentous apparatus of the knee. Clinically significant laxity is noted in an injury to at least two ligaments. The posterior drawer test is used to assess for PCL tears [19]. Hemarthrosis is not indicative of a collateral ligament sprain and not detected in $40 \%$ of arthroscopic findings with nonoperative treatment to follow. Acute hemarthrosis of the knee is diagnosed with a PCL injury in one third of the cases [20]. Arthroscopy is considered to be the most accurate diagnostic tool available for the evaluation of ligament injuries [20]. Endoscopic evaluation of posterolateral complex is difficult in PCL injuries.

PCL tears are typically produced by external trauma such as the classic "dashboard injury" resulting from a posteriorly directed force on the anterior aspect of the proximal tibia with the knee flexed. In athletics, the typical mechanism of isolated PCL tears is a direct blow to the anterior tibia or a fall onto the knee with the foot in a plantar flexed position. Football, rugby and skiing are among the sports with highest incidence of PCL tears [21]. Non-contact mechanisms, such as hyperflexion or hyperextension, are less common [22]. Symptoms depend upon the injury mechanism (high- or low-energy) as well as chronicity. Stiffness, swelling and pain on the posterior aspect of the knee are typical symptoms, while anterior knee pain and instability when descending stairs are more often associated with chronic isolated tears [23, 24].

Physical examination for acute conditions of the knee can be difficult due to pain and guarding. The findings of clinical examination, mechanism of injury and symptom presentation are important for making an accurate diagnosis of PCL deficiency. It is critical to examine the contralateral knee first and compare it to the injured knee. The posterior drawer test is performed at $90^{\circ}$ of flexion, and has a sensitivity of $90 \%$ and a specificity of $99 \%$ [25]. A false-positive pseudo-Lachman test for the ACL is not uncommon. 
An important indication of PCL deficiency is a positive Clancy sign, which is a loss of the normal anteromedial and lateral prominences of the tibial plateau beneath the femoral condyles, as determined by palpation with the knee at $90^{\circ}$ of flexion and neutral rotation. The Godfrey test is performed with the hip and knee flexed to $90^{\circ}$ while the examiner supports the leg. If the PCL is torn, an abnormal contour may be evident at the proximal anterior tibia viewed from a lateral position. The quadriceps active test is performed with the patient supine and the knee $90^{\circ}$ flexed while the examiner stabilizes the foot. A positive test is observed when the patient performs an isometric quadriceps contraction.

In a study by Moulton et al. (2015) side-to-side differences in internal rotation were assessed under anesthesia by measuring anterior tibial tubercle excursion. The supine internal rotation test performed between $60^{\circ}$ and $120^{\circ}$ resulted in $95.5 \%$ sensitive and $97.1 \%$ specific in diagnosing a grade III PCL tear [26]. Additional tests are utilized to evaluate for possible combined ligament and concomitant intraarticular injury. In a systematic review, Kopkow et al. (2013) reported that the quadriceps active test is the most specific test for detecting PCL deficiency [27].

Standard radiographs are performed to detect the presence of fractures, bony avulsions, joint space assessment and tibiofemoral joint congruity [28]. Stress radiography allows for comparison of the magnitude of posterior tibial displacement on the femur between the injured and uninjured knees. A partial PCL tear is diagnosed with $0-7 \mathrm{~mm}$ of side-toside difference in posterior displacement, $8-11 \mathrm{~mm}$ constitutes an isolated complete PCL tear and $\geqslant 12$ $\mathrm{mm}$ of posterior translation constitutes a combined PCL and posterolateral corner or posteromedial corner knee injury [29].

Magnetic resonance imaging (MRI) is an important adjunct to the diagnosis of PCL tears with a sensitivity, specificity and accuracy of nearly 100 $\%$ for the diagnosis of acute PCL injuries $[11,30$, 31]. MRI has lower sensitivity in the evaluation of chronic PCL tears because the signal and shape of the PCL can be deceptively restored through the healing process in chronic cases despite residual laxity being present. Therefore, stress radiographs are strongly advocated to diagnose chronic PCL tears [32].

A recent MRI study by Wilson et al. (2016) quantified T2 and T2-weighed PCL properties in asymptomatic population of patients. The authors reported significant differences in $\mathrm{T} 2$ values in distal, middle and proximal regions of the PCL providing a feasible baseline to compare acute and chronic PCL tears. MRI is also important to diagnose concurrent meniscal, cartilage, and ligamentous injuries of the knee[31].

In addition, it is important to radiographically evaluate a sagittal plane tibial slope, especially in chronic or revision cases. Patients with isolated PCL tears and a decreased posterior tibial slope may be candidates for a high tibial osteotomy to increase their slope and thereby decrease graft forces and reconstruction graft failure rate. Varus and valgus stress radiographs are also helpful in objectively diagnosing suspected concurrent medial and/or lateral sided injuries based on physical exam findings [30-32].

The combination of the clinical tests, radiological assessment are used to diagnose PCL tear and identify treatment strategy. Nonoperative treatment is an option for isolated acute PCL tears with not more than $10 \mathrm{~mm}$ of posterior tibial translation decreasing with internal rotation of the tibia; knee rotation of not more than 50; the absence of noticeable knee varus or valgus alignment, i.e. grades I and II PCL tears. Surgical treatment is indicated in the absence of the above characteristics and in the presence of other impaired ligamentous or bony structures of the knee.

Approaches to the treatment of complete isolated PCL tears remains controversial. Some studies have reported good outcomes after conservative treatment of partial PCL tears, while others have reported poor results at long-term follow-up with disabling symptoms and functional limitations. Most authors agree that partial isolated PCL tears should be treated nonoperatively. However, disturbed biomechanics, redistribution of forces in the knee, rotational and valgus/varus instability due to PCL tear contribute to articular cartilage degeneration and resultant secondary osteoarthritis of the injured knee. Patellofemoral and medial compartments are more vulnerable in PCL-deficient knees. Complete PCL tears treated non-operatively have been reported to increase the risk of degenerative changes of the medial and patellofemoral compartments at a long term, and to be associated with poor function [33].

A set of primarily conservative management and rehabilitation strategies has been established for isolated PCL injuries [34]. In 1980, Trickey E. et al. termed the PCL as the central pivot point of the knee and recommended early surgical treatment of all PCL tears [35]. Dandy J. and Pusey R. (1982) reported that 14 of 20 patients with PCL tears treated conservatively had generalized pain in the knee at a mean follow-up of 7 years [36]. Keller P.M. et al. 
(1993) evaluated 40 patients with isolated PCL tears treated conservatively, $90 \%$ of whom experienced pain while $65 \%$ reported limited activity level despite good muscle strength at a 6-year follow-up [34]. In a study of 25 patients with PCL tears, Parolie J. and Bergfeld J. (1986) reported that nearly half of the patients reported pain and one third of the cases had radiographic evidence of knee osteoarthrosis [37]. Fowler P.J. and Messich S.S. (1987) reviewed 13 PCL injured patients treated conservatively and 10 were subjectively dissatisfied with the level of physical activity [38]. Signs of cartilage degeneration were revealed in the medial compartment of the knee by Clancy W., Sutherland T. (1994) in 191 patients with posterior instability [39]. Therefore, surgical treatment is recommended for complete PCL tears and combined injuries to regain stability and function.

Conservative treatment is employed as one of the options for isolated acute PCL tears and dynamic PCL braces can be useful for this. It has been reported that because the PCL has a variable tension throughout knee ROM, a properly designed PCL brace should apply a force that varies with knee flexion angle [40, 41]. This led to the design of functional dynamic force braces, which provide significantly greater applied force at $45^{\circ}$ of flexion that increases with knee flexion angle [30, 41]. However, further clinical studies are necessary to determine whether posterior knee laxity is improved long-term following treatment of PCL tears with a dynamic brace. Dynamic bracing is indicated both for nonoperative treatment and postoperative rehabilitation of PCL tears.

If nonoperative treatment fails, operative treatment is indicated. The indications for surgical treatment of chronic PCL injuries also show controversies on the precise indications for ligament reconstruction due to the lack of reliable findings and traumatic approaches to the PCL attachments to the femur and tibia. Cosmetically unacceptable scars are a contraindication to open PCL reconstructions.

Several techniques for PCL reconstruction have been offered, depending on tibial graft fixation (transtibial tunnel and tibial inlay techniques), the bundles addressed (single-bundle or double-bundle), and the type of graft used [42, 43]. Arthroscopic PCL reconstruction features several benefits including less traumatic procedure, slightly impaired proprioceptive function, more accurate positioning of bone tunnels and good cosmetic effect.

Articular cartilage of the knee has a role of the secondary stabilizer with the congruent articular surfaces provided, and its trophics and anatomy is crucial for patients with ligament deficiency. The disturbed biomechanics, re-distribution of forces in the knee, rotational and valgus/varus instability due to PCL tear contribute to articular cartilage degeneration and resultant secondary osteoarthritis of the injured knee. Combined use of glucosamine, chondroitin sulfate as Symptomatic Slow-Acting Drugs in Osteoarthritis (SYSADOAs) may be expected to have a protective effect for the condition. As a basic component of the cartilage and synovial fluid chondroitin sulfate has been shown to have a chondroprotective effect through anabolic and anticatabolic processes in the cartilaginous metabolism. Sulfates are involved in glycosaminoglycans synthesis, and chondroitin promotes water retention within joints due to the net negative charge providing the resilience and elasticity of the tissues. Glucosamine is a building block for articular cartilage's matrix and is used to produce proteoglycans, glycosaminoglycans, chondroitin and hyaluronic acid [44].

In vitro, a combination of glucosamine hydrochloride and chondroitin sulfate acted synergistically in stimulating glycosaminoglycan synthesis (96.6\%). Glucosamine alone increased glycosaminoglycan production by $32 \%$ and chondroitin by $32 \%$. A combination of glucosamine and chondroitin was shown to result in collagen synthesis increased by $69 \%$ in ligament cells, $56 \%$ in chondrocytes and $22 \%$ that is important for joint stability [45]. Therefore, a combination of glucosamine and chondroitin (glucosamine-chondroitin sulfate) as a basic therapy for patients with injured knee ligaments can be indicated for prevention of cartilage destruction increasing strength of ligaments and ultimately improving joint biomechanics.

In clinical settings, combined use of chondroitin sulfate and glucosamine has been shown to inhibit cartilage destruction processes and stimulate cartilage regeneration, improving pain, stiffness and providing anti-inflammatory effects. Allocation to the dietary supplement combination (glucosamine sulfate $1500 \mathrm{mg}$, chondroitin sulfate $800 \mathrm{mg}$ ) resulted in a statistically significant $(p=0.046)$ reduction of joint space narrowing compared to placebo; no significant structural effect for the single treatment allocations was detected. A therapeutic dose of glucosamine sulfate $500 \mathrm{mg}$ and chondroitin sulfate $400 \mathrm{mg}$ 3 times daily was shown to exert structure-modifying effects. Treatment with chondroitin sulfate combined with glucosamine for nine months daily resulted in significant reduction in knee pain and NSAID rejection in one third of the patients with $83 \%$ having 
US verified structural changes in the knee: reduction in synovial thickness, suprapatellar pouch, size of popliteal cyst and the extent of periarticular changes [45]. A combined use of glucosamine sulfate and chondroitin sulfate administered in adequate doses can inhibit joint destruction. Several trials showed a 2-fold decrease in THR $(\mathrm{p}=0.024)$ and a $57 \%$ decrease in a relative risk due to chondroprotective effects of chondroitin sulfate and glucosamine at 8 -year follow-up [46, 47].

\section{CONCLUSION}

The literature reviewed for reports on PCL injuries showed a variety of approaches used to treat PCL tears. Controversy still exists regarding the decisions for non-operative versus operative treatment, and the optimal surgical technique. Nonoperative treatment has long been recommended for PCL tears but a higher rate of poor outcomes suggested using a surgical approach as a better option. Nonsurgical treatment is reserved for PCL injury with absent knee laxity, absent pain and less than $10 \mathrm{~mm}$ of posterior tibial translation. Arthroscopic PCL reconstruction can be advocated for the above characteristics being present.

Articular cartilage of the knee has a role of the secondary stabilizer with the congruent articular surfaces provided, and its trophics and anatomy is crucial for patients with ligament deficiency. The disturbed biomechanics, re-distribution of forces in the knee, rotational and valgus/varus instability due to PCL tear contribute to articular cartilage degeneration and resultant secondary osteoarthritis of the injured knee. Patellofemoral and medial compartments are more vulnerable in PCL-deficient knees. Prevention of secondary osteoarthritis is critical for patients with PCL tears. A combination of glucosamine chondroitin sulfate has been shown to have a protective effect for the condition improving trophics of the cartilagineous and ligamentous tissues, accelerating metabolism of the articular cartilage facilitating the regeneration to defer onset and severity of knee osteoarthritis.

\section{REFERENCES}

1. Lee Y.S., Lee O.S., Lee S.H. Return to Sports After Athletes Undergo Meniscal Surgery: A Systematic Review. Clin. J. Sport Med., 2017, vol. 29, no. 1, pp. 29-36. DOI: 10.1097/JSM.0000000000000500.

2. Lundblad M., Waldén M., Magnusson H., Karlsson J., Ekstrand J. The UEFA injury study: 11-year data concerning 346 MCL injuries and time to return to play. Br. J. Sports Med., 2013, vol. 47, no. 12, pp. 759-762. DOI: 10.1136/bjsports-2013-092305.

3. Jacobi M., Reischl N., Wahl P., Gautier E., Jakob R.P. Acute isolated injury of the posterior cruciate ligament treated by a dynamic anterior drawer brace: a preliminary report. J. Bone Joint Surg. Br., 2010, vol. 92, no. 10, pp. 1381-1384. DOI: 10.1302/0301-620 X.92B10.24807.

4. Logerstedt D.S., Scalzitti D., Risberg M.A., Engebretsen L., Webster K.E., Feller J., Snyder-Mackler L., Axe M.J., McDonoug C.M. Knee Stability and Movement Coordination Impairments: Knee Ligament Sprain Revision 2017. J. Orthop. Sports Phys. Ther., 2017, vol. 47, no. 11, pp. A1-A47. DOI: 10.2519/jospt.2017.0303.

5. Joseph A.M., Collins C.L., Henke N.M., Yard E.E., Fields S.K., Comstock R.D. A multisport epidemiologic comparison of anterior cruciate ligament injuries in high school athletics. J. Athl. Train., 2013, vol. 48, no. 6, pp. 810-817. DOI: 10.4085/1062-6050-48.6.03.

6. Bai X.S., Thomas J.M., Ha A.S. Surgical Correction of Articular Damage in the Knee: Osteoarticular Transplantation to Joint Reconstruction. Semin. Musculoskelet. Radiol., 2017, vol. 21, no. 2, pp. 147-164. DOI: 10.1055/s-0037-1599211.

7. Beziazychnaia O.V. Lechebnaia fizicheskaia kultura v kompleksnoi fizicheskoi reabilitatsii posle artroskopicheskoi operatsii po povodu razryva sviazok kolennogo sustava [Exercise therapy in complex physical rehabilitation after arthroscopic surgery for the knee ligament tear]. Slobozhanskii Naukovo-Sportivnii Visnik, 2013, no. 2 (35), pp. 144-146. (in Russian)

8. Kuznetsov I.A., Fomin N.F., Shulepov D.A., Salikhov M.R. Sovremennye podkhody k khirurgicheskomu lecheniiu khronicheskoi zadnei nestabilnosti kolennogo sustava (obzor literatury) [Current approaches to surgical treatment of the knee chronic posterior instability (Review of the literature)]. Travmatologiia i Ortopediia Rossii, 2015, no. 1, pp. 95-105. (in Russian)

9. Dold A.P., Swensen S., Strauss E., Alaia M. The Posteromedial Corner of the Knee: Anatomy, Pathology, and Management Strategies. J. Am. Acad. Orthop. Surg., 2017, vol. 25, no. 11, pp. 752-761. DOI: 10.5435/JAAOS-D-16-00020.

10.Georgiadis A.G., Mohammad F.H., Mizerik K.T., Nypaver T.J., Shepard A.D. Changing presentation of knee dislocation and vascular injury from high-energy trauma to low-energy falls in the morbidly obese. J. Vasc. Surg., 2013, vol. 57, no. 5, pp. 11961203. DOI: $10.1016 /$ j.jvs.2012.11.067.

11.Bedi A., Musahl V., Cowan J.B. Management of posterior cruciate ligament injuries: an evidence-based review. J. Am. Acad. Orthop. Surg., 2016, vol. 24, no. 5, pp. 277-289. DOI: 10.5435/JAAOS-D-14-00326.

12.Logan M., Williams A., Lavelle J., Gedroyc W., Freeman M. The effect of posterior cruciate ligament deficiency on knee kinematics. Am. J. Sports Med., 2004, vol. 32, no. 8, pp. 1915-1922.

13.Kennedy N.I., LaPrade R.F., Goldsmith M.T., Faucett S.C., Rasmussen M.T., Coatney G.A., Engebretsen L., Wijdicks C.A. Posterior cruciate ligament graft fixation angles, part 1: biomechanical evaluation for anatomic single-bundler reconstruction. Am. J. Sports Med., 2014, vol. 42, no. 10, pp. 2338-2345. DOI: 10.1177/0363546514541225.

14.Anderson C.J., Ziegler C.G., Wijdicks C.A., Engebretsen L., LaPrade R.F. Arthroscopically pertinent anatomy of the anterolateral and posteromedial bundles of the posterior cruciate ligament. J. Bone Joint Surg. Am., 2012, vol. 94, no. 21, pp. $1936-1945$. DOI: 10.2106/JBJS.K.01710. 
15.Kennedy N.I., Wijdicks C.A., Goldsmith M.T., Michalski M.P., Devitt B.M., Arøen A., Engebretsen L., LaPrade R.F. Kinematic analysis of the posterior cruciate ligament, part 1: the individual and collective function of the anterolateral and posteromedial bundles. Am. J. Sports Med., 2013, vol. 41, no. 12, pp. 2828-2838. DOI: 10.1177/0363546513504287.

16.Boutefnouchet T., Bentayeb M., Qadri Q., Ali S. Long-term outcomes following single-bundle transtibial arthroscopic posterior cruciate ligament reconstruction. Int. Orthop., 2013, vol. 37, no. 2, pp. 337-343. DOI: 10.1007/s00264-012-1609-3.

17.Harner C.D., Waltrip R.L., Bennett C.H., Francis K.A., Cole B., Irrgang J.J. Surgical management of knee dislocations. J. Bone Joint. Surg. Am., 2004, vol. 86, no. 2, pp. 262-273.

18.Clark D., Metcalfe A., Wogan C., Mandalia V., Eldridge J. Adolescent patellar instability: current concepts review. Bone Joint J., 2017, vol. 99-B, no. 2, pp. 159-170. DOI: 10.1302/0301-620X.99B2.BJJ-2016-0256.R1.

19.De Campos G.C., Teixeira P.E.P., Castro A., Alves Junior W.M. Femoral positioning influences ipsi- and contralateral anterior cruciate ligament rupture following its reconstruction: Systematic review and meta-analysis. World J. Orthop., 2017, vol. 8, no. 8, pp. 644-650. DOI: 10.5312/wjo.v8.i8.644.

20.Fanelli G.C., Giannotti B.F., Edson C.J. Arthroscopically assisted combined posterior cruciate ligament/posterior lateral complex reconstruction. Arthroscopy, 1996, vol. 12, no. 5, pp. 521-530.

21.Lubowitz J.H., Brand J.C., Provencher M.T., Rossi M.J. Systematic reviews keep arthroscopy up to date. Arthroscopy, 2016, vol. 32, no. 2, pp. 237. DOI: 10.1016/j.arthro.2015.12.002.

22.Strickland J.P., Fester E.W., Noyes F.R. Lateral, posterior, and cruciate knee anatomy. Noyes F.R., ed. Noyes' Knee Disorders: surgery, rehabilitation, clinical outcomes. Philadelphia, Saunders, 2009, pp. 20-43.

23.Lee S.H., Jung Y.B., Lee H.J., Jung H.J., Kim S.H. Revision posterior cruciate ligament reconstruction using a modified tibial-inlay double-bundle technique. J. Bone Joint Surg. Am., 2012, vol. 94, no. 6, pp. 516-522. DOI: 10.2106/JBJS.K.00030.

24.Lee D.Y., Kim D.H., Kim H.J., Nam D.C., Park J.S., Hwang S.C. Biomechanical Comparison of Single-Bundle and DoubleBundle Posterior Cruciate Ligament Reconstruction: A Systematic Review and Meta-Analysis. JBJS Rev., 2017, vol.5, no. 10, p. e6. DOI: 10.2106/JBJS.RVW.17.00008.

25.Markolf K.L., Feeley B.T., Tejwani S.G., Martin D.E., McAllister D.R. Changes in knee laxity and ligament force after sectioning the posteromedial bundle of the posterior cruciate ligament. Arthroscopy, 2006, vol. 22, no. 10, pp. 1100-1106.

26.Moulton S.G., Cram T.R., James E.W., Dornan G.J., Kennedy N.I., LaPrade R.F. The Supine internal rotation test: a pilot study evaluating tibial internal rotation in grade III posterior cruciate ligament tears. Orthop. J. Sports Med., 2015, vol. 3, no. 2, 2325967115572135. DOI: 10.1177/2325967115572135.

27.Kopkow C., Freiberg A., Kirschner S., Seidler A., Schmitt J. Physical examination tests for the diagnosis of posterior cruciate ligament rupture: a systematic review. J. Orthop. Sports Phys. Ther., 2013, vol. 43, no. 11, pp. 804-813. DOI: 10.2519/jospt.2013.4906.

28.Spiridonov S.I., Slinkard N.J., LaPrade R.F. Isolated and combined grade-III posterior cruciate ligament tears treated with doublebundle reconstruction with use of endoscopically placed femoral tunnels and grafts: operative technique and clinical outcomes. J. Bone Joint Surg. Am., 2011, vol. 93, no. 19, pp. 1773-1780. DOI: 10.2106/JBJS.J.01638.

29.Jackman T., LaPrade R.F., Pontinen T., Lender P.A. Intraobserver and interobserver reliability of the kneeling technique of stress radiography for the evaluation of posterior knee laxity. Am. J. Sports Med., 2008, vol. 36, no. 8, pp. 1571-1576. DOI: $10.1177 / 0363546508315897$.

30.LaPrade R.F., Smith S.D., Wilson K.J., Wijdicks C.A. Quantification of functional brace forces for posterior cruciate ligament injuries on the knee joint: an in vivo investigation. Knee Surg. Sports Traumatol. Arthrosc., 2015, vol. 23, no. 10, pp. $3070-3076$. DOI: $10.1007 / \mathrm{s} 00167-014-3238-4$.

31.Wilson K.J., Surowiec R.K., Ho C.P., Devitt B.M., Fripp J., Smith W.S., Spiegl U.J., Dornan G.J., LaPrade R.F. Quantifiable imaging biomarkers for evaluation of the posterior cruciate ligament using 3-T magnetic resonance imaging: a feasibility study. Orthop. J. Sports Med., 2016, vol. 4, no. 4, p. 2325967116639044 . DOI: 10.1177/2325967116639044.

32.LaPrade R.F., Heikes C., Bakker A.J., Jakobsen R.B. The reproducibility and repeatability of varus stress radiographs in the assessment of isolated / fibular collateral ligament and grade-III posterolateral knee injuries. An in vitro biomechanical study. J. Bone Joint Surg. Am., 2008, vol. 90, no. 10, pp. 2069-2076. DOI: 10.2106/JBJS.G.00979.

33.Gill T.J., DeFrate L.E., Wang C., Carey C.T., Zayontz S., Zarins B., Li G. The effect of posterior cruciate ligament reconstruction on patellofemoral contact pressures in the knee joint under simulated muscle loads. Am. J. Sports Med., 2004, vol. 32, no. 1, pp. 109-115.

34.Keller P.M., Shelbourne K.D., McCarroll J.R., Rettig A.C. Nonoperatively treated isolated posterior cruciate ligament injuries. Am. J. Sports Med., 1993, vol. 21, no. 1, pp. 132-136.

35.Trickey E.L. Injuries to the posterior cruciate ligament: diagnosis and treatment of early injuries and reconstruction of late instability. Clin. Orthop. Relat. Res., 1980, no. 147, pp. 76-81.

36.Dandy D.J., Pusey R.J. The long-term results of unrepaired tears of the posterior cruciate ligament. J. Bone Joint Surg. Br., 1982, vol. 64, no. 1, pp. 92-94.

37.Parolie J.M., Bergfeld J.A. Long-term results of nonoperative treatment of isolated posterior cruciate ligament injuries in the athlete. Am. J. Sports Med., 1986, vol. 14, no. 1, pp. 35-38.

38.Fowler P.J., Messieh S.S. Isolated posterior cruciate ligament injuries in athletes. Am. J. Sports Med., 1987, vol. 15, no. 6, pp. $553-557$. 39.Clancy W.G. Jr., Sutherland T.B. Combined posterior cruciate ligament injuries. Clin. Sports Med., 1994, vol. 13, no. 3, pp. $629-647$.

40.Shelbourne K.D., Clark M., Gray T. Minimum 10-year follow-up of patients after an acute, isolated posterior cruciate ligament injury treated nonoperatively. Am. J. Sports Med., 2013, vol. 41, no. 7, pp. 1526-1533. DOI: 10.1177/0363546513486771.

41.Jansson K.S., Costello K.E., O’Brien L., Wijdicks C.A., LaPrade R.F. A historical perspective of PCL bracing. Knee Surg. Sports Traumatol. Arthrosc., 2013, vol. 21, no. 5, pp. 1064-1070. DOI: 10.1007/s00167-012-2048-9.

42.Panchal H.B., Sekiya J.K. Open tibial inlay versus arthroscopic transtibial posterior cruciate ligament reconstructions. Arthroscopy, 2011, vol. 27, no. 9, pp. 1289-1295. DOI: 10.1016/j.arthro.2011.04.007.

43.Wijdicks C.A., Kennedy N.I., Goldsmith M.T., Devitt B.M., Michalski M.P., Årøen A., Engebretsen L., LaPrade R.F. Kinematic analysis of the posterior cruciate ligament, part 2: a comparison of anatomic single- versus double-bundle reconstruction. Am. J. Sports Med., 2013, vol. 41, no. 12, pp. 2839-2848. DOI: 10.1177/0363546513504384. 
44.Jerosch J. Effects of Glucosamine and Chondroitin Sulfate on Cartilage Metabolism in OA: Outlook on Other Nutrient Partners Especially Omega-3 Fatty Acids. Int. J. Rheumatol., 2011, vol. 2011, p. 969012. DOI: 10.1155/2011/969012.

45.Chichasova N.V. Sovremennye rekomendatsii po lecheniiu osteoartroza [Current recommendations on osteoarthrosis treatment]. Consilium Medicum, 2016, vol.18, no. 2, pp. 124-133. (in Russian)

46.Bruyere O., Pavelka K., Rovati L.C., Gatterová J., Giacovelli G., Olejarová M., Deroisy R., Reginster J.Y. Total joint replacement after glucosamine sulphate treatment in knee osteoarthritis: results of a mean 8-year observation of patients from two previous 3-year, randomised, placebo-controlled trials. Osteoarthritis Cartilage, 2008, vol. 16, no. 2, pp. 254-260.

47.Mikhailova A.S.,Tepliakova O.V., Sokolova L.A. Vliianie lokalnoi terapii gonartroza preparatami gialuronovoi kisloty razlichnoi molekuliarnoi massy na dinamiku algofunktsionalnykh pokazatelei [The effect of gonarthrosis local therapy using hyaluronic acid preparations of different molecular mass on the dynamics of algofunctional values]. Farmateka, 2011, no. 19, pp. 74-78. (in Russian)

Received: 31.05.2019

\section{Information about the authors:}

1.Andrey V. Korolev, M.D., Ph.D., Professor, European Clinic of Sports Traumatology and Orthopaedics (ECSTO), Moscow, Russian Federation, Peoples Friendship University of Russia, Moscow, Russian Federation,

Email: akorolev@emcmos.ru

2.Alexey P. Afanasyev, M.D., Ph.D.,

European Clinic of Sports Traumatology and Orthopaedics (ECSTO), Moscow, Russian Federation

3. Denis O. Gerasimov, M.D., Ph.D.,

European Clinic of Sports Traumatology and Orthopaedics (ECSTO), Moscow, Russian Federation

4.Dmitriy O. Ilyin, M.D., Ph.D.,

European clinic of sports traumatology and orthopedics (ECSTO), Moscow, Russian Federation,

Email: dilyin@emcmos.ru

5. Michael S. Ryazantsev, M.D., Ph.D.,

European clinic of sports traumatology and orthopedics (ECSTO), Moscow, Russian Federation,

Email: mryazantsev@emcmos.ru

6. Pavel M. Kadantsev, M.D.,

European Clinic of Sports Traumatology and Orthopaedics (ECSTO), Moscow, Russian Federation,

Peoples Friendship University of Russia, Moscow, Russian Federation,

Email: pkadantsev@emcmos.ru 